\title{
Protective effect of crocin and voluntary exercise against oxidative stress in the heart of high-fat diet-induced type 2 diabetic rats
}

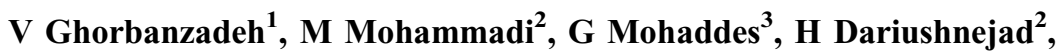 \\ L Chodari $^{1}$, S Mohammadi ${ }^{2}$ \\ ${ }^{1}$ Student Research Committee, Tabriz University of Medical Sciences, Tabriz, Iran \\ ${ }^{2}$ Drug Applied Research Center, Tabriz University of Medical Sciences, Tabriz, Iran \\ ${ }^{3}$ Neuroscience Research Center, Tabriz University of Medical Sciences, Tabriz, Iran
}

Received: April 1, 2016

Accepted: October 26, 2016

\begin{abstract}
Background: Oxidative stress plays a critical role in the pathogenesis and progression of type 2 diabetes and diabeticassociated cardiovascular complications. This study investigated the impact of crocin combined with voluntary exercise on heart oxidative stress indicator in high-fat diet-induced type 2 diabetic rats. Materials and methods: Rats were divided into four groups: diabetes, diabetic-crocin, diabetic-voluntary exercise, diabetic-crocin-voluntary exercise. Type 2 diabetes was induced by high-fat diet (4 weeks) and injection of streptozotocin (intraperitoneally, $35 \mathrm{mg} / \mathrm{kg})$. Animals received crocin orally $(50 \mathrm{mg} / \mathrm{kg})$; voluntary exercise was performed alone or combined with crocin treatment for 8 weeks. Finally, malondialdehyde (MDA), activity of antioxidant enzymes, superoxide dismutase (SOD), glutathione peroxidase (GPx), and catalase (CAT) were measured spectrophotometrically. Results: Treatment of diabetic rats with crocin and exercise significantly decreased the levels of MDA $(p<0.001)$ and increased the activity of SOD, GPx, and CAT compared with the untreated diabetic group. In addition, combination of exercise and crocin amplified their effect on antioxidant levels in the heart tissue of type 2 diabetic rats. Conclusion: We suggest that a combination of crocin with voluntary exercise treatment may cause more beneficial effects in antioxidant defense system of heart tissues than the use of crocin or voluntary exercise alone.
\end{abstract}

Keywords: type 2 diabetes, crocin, voluntary exercise, antioxidant, oxidative stress

\section{Introduction}

Diabetes mellitus (DM) is a worldwide health problem associated with increased cardiovascular complications and cardiovascular diseases (49).

Type $2 \mathrm{DM}$ is recognized as the etiology of over $80 \%$ of all diabetics and is dramatically increasing in incidence as a result of changes in human behavior and increased body mass index (27). Hyperglycemia, consequence of islet insufficiency, resulting from uncontrolled glucose regulation is widely recognized as the causal link between diabetes and diabetic complications (9).

From the studies, it is clear that hyperglycemia induces reactive oxygen species (ROS) overproduction (10). However, in response to oxidative stress, antioxidant enzymes that include superoxide dismutase (SOD), glutathione peroxidase (GPx), catalase (CAT), and

Corresponding author: Dr. Mustafa Mohammadi, PhD

Drug Applied Research Center, Tabriz University of Medical Sciences

Golgasht Ave., Tabriz 51666-14766, Iran

Phone: +98 411 3364664; Fax: +98 411 33364664; E-mail: m.mohammadin@yahoo.com 
small molecule substances such as vitamins $\mathrm{C}$ and $\mathrm{E}$ are believed to be induced to protect cellular functions, which maintain in vivo homeostasis (15). There are evidences that the antioxidant defense is destroyed in diabetic patients, proposing a disturbed scavenging capacity of detrimental free radicals (36). Therefore, it became obvious that improving oxidative stress might be a useful strategy for decreasing diabetic complications.

Crocin, an abundant antioxidant constituent of Crocus sativus L. (saffron), exhibits a variety of pharmacological effects on the nervous (48), cardiac (18), and renal (21) systems. Several studies have indicated that saffron and its major constituent, crocin, has hypoglycemic effects that seem to be exerted through the stimulation of glucose uptake by peripheral tissues (45), inhibition of intestinal glucose absorption (46), inhibition of endogenous glucose production (11), regeneration, and stimulation of $\beta$-cells of islets of Langerhans to release more insulin $(11,43)$. Recently, it was reported that crocin exhibited significant radical scavenging activity and thus antioxidant activity (6). Hosseinzadeh et al. (21) have shown that crocin is a useful agent for the prevention of renal ischemia-reperfusion (IR)-induced oxidative injury in rats. Furthermore, in our previous study, we reported that crocin combined with voluntary exercise improved insulin resistance and reduced glucose levels in the heart of diabetic rats (16). Samarghandian et al. (35) have indicated that saffron has antihyperglycemic and hypoglycemic properties by the modulation of oxidative stress in streptozotocin (STZ) diabetic rats.

Physical activity has been considered to reduce diabetic complications (28). A part of the protective effect of physical exercise has been hypothesized to derive from antioxidant effects. Lee et al. (29) reported that exercise training could improve coronary vascular function by suppressing oxidative stress in a type 2 diabetes. Kupai et al. (26) showed the cardioprotective effect of voluntary exercise in the Goto-Kakizaki type 2 diabetic rat heart against IR injury. It has been shown that exercise training increases antioxidant enzymes and reduces lipid peroxidation, which can reverse oxidative stress in animal models (8). Studies have been suggested that forced exercise induces oxidative stress through the production of ROS and can cause damage to organs (25). Voluntary exercise is ranged in mild/moderate exercise and is a useful therapeutic approach in diabetic complications such as cardiovascular diseases. In the animal model of voluntary exercise, the animal has free access to a running wheel and utilizes the wheel according to its physiological threshold for physical activity (12). Therefore, considering the antioxidant effects of crocin and voluntary exercise, this study was designed to evaluate the antioxidant activity of crocin in combination with voluntary exercise in the heart tissue of high-fat diet-induced type 2 diabetic rats.

\section{Materials and Methods}

\section{Animals}

All animals used in this study were provided by the Tabriz Medical Faculty (Tabriz, Iran). Animals were caged at a constant room temperature of $24{ }^{\circ} \mathrm{C}$, a relative humidity of $50 \%$, and a 12-h dark/light cycle with access to food and water ad libitum. All rats were kept at four rats per cage for the duration of the study except rats in the exercise groups that were housed singly. This study was approved by the Animal Ethics Committee in accordance with the instructions for the care and use of laboratory animals prepared by Tabriz University of Medical Sciences (permit number 93/5/4). 

$(n=7)$ :

Twenty-eight male Wistar rats (200-250 g) were randomly divided into four groups

1. Diabetic (Dia): Rats that received high-fat diet (4 weeks) and low dose of STZ (35 mg/kg)

2. Diabetic-crocin (Dia-Cro): Diabetic rats that received crocin $(50 \mathrm{mg} / \mathrm{kg}, 8$ weeks)

3. Diabetic-voluntary exercise (Dia-Exe): Diabetic rats that performed exercise ( 8 weeks)

4. Diabetic-voluntary exercise-crocin (Dia-Cro-Exe): Diabetic rats that received crocin and performed exercise.

Crocin (Sigma) was gavaged $(50 \mathrm{mg} / \mathrm{kg}) 6$ days a week for 8 weeks $(19,31)$. For the assessment of voluntary exercise, rats were housed individually in a cage containing a wheel (1.00 m circumference, Tajhiz Gostar, Tehran, Iran). This stainless-steel running wheel was equipped with a digital magnetic counter that was activated by wheel rotation. Each exercising rat had a separate running wheel in its cage that allowed it to run voluntarily during 8 weeks of the study. Data of rats with running distance lower than 2,000 $\mathrm{m} /$ day were eliminated before statistical analysis (39).

\section{Induction of diabetes with high-fat diet and streptozotocin}

STZ was obtained from Sigma for inducing diabetes. Male rats were fed with high-fat diet comprising $22 \%$ fat, $48 \%$ carbohydrate, and $20 \%$ protein in blend with standard laboratory chow consisting of 5\% fat, $53 \%$ carbohydrate, and $23 \%$ protein for 4 weeks. After the period of dietary manipulation, rats were injected intraperitoneally (i.p.) with low dose of STZ (35 mg/kg) (37). Then, animals had free access to water and standard food $(2,47)$. After $72 \mathrm{~h}$ of STZ administration, rats with fasting blood glucose of $\geq 300 \mathrm{mg} / \mathrm{dL}$ were considered diabetic.

\section{Heart tissue preparation}

On the final day of experiment, rats were sacrificed under anesthesia with ketamine/xylazine $(88 / 10 \mathrm{mg} / \mathrm{kg}$, i.p.). Heart tissue was immediately removed and washed with $0.9 \%$ saline solution. Then, hearts were excised, frozen in liquid nitrogen, and stored at deep freeze $\left(-70{ }^{\circ} \mathrm{C}\right)$ for biochemical measurements. For antioxidant activity measurement, heart samples were homogenized in $1.15 \% \mathrm{KCl}$ solution. The homogenates were centrifuged at $1,000 \mathrm{rpm}$ for $1 \mathrm{~min}$ at $4{ }^{\circ} \mathrm{C}$. The tissue homogenate was then stored at $-20^{\circ} \mathrm{C}$ for GPx, SOD and CAT activities, and malondialdehyde (MDA) measurements.

\section{Lipid peroxidation measurement: Malondialdehyde}

Lipid peroxides are unstable and decompose to form a series of compounds including reactive carbonyl compounds. Polyunsaturated fatty acid peroxides generate MDA and its measurement has been used as an indicator of lipid peroxidation, which is analyzed by measuring thiobarbituric acid reactive substances (TBARSs) in homogenates. Briefly, the samples $(250 \mu \mathrm{L})$ were mixed with $1 \mathrm{~mL}$ of $10 \%$ trichloroacetic acid (TCA) and $1 \mathrm{~mL}$ of $0.67 \%$ thiobarbituric acid. Then, samples were heated in a boiling water bath for $15 \mathrm{~min}$ and then n-butyl alcohol $(2: 1 \mathrm{v}: \mathrm{v})$ was added to the solution. After centrifugation $(3,500 \times g, 5 \mathrm{~min})$ at room temperature, TBARS was determined from the absorbance at $535 \mathrm{~nm}$, using a spectrophotometer (Pharmacia Biotech, England) and the values obtained were expressed as nmol per $100 \mathrm{mg}$ tissue protein. The intra- and inter-assay coefficient of variations of measurements performed on the same sample were less than $5 \%$ and $7 \%$, respectively (14). 


\section{Superoxide dismutase measurement}

SOD activity was determined using a RANSOD kit (Randox, Crumlin, UK). SOD activity was measured at $505 \mathrm{~nm}$ by a spectrophotometer. In this method, xanthine and xanthine oxidase were used to generate superoxide radicals that were able to react with 2-[4-iodophenyl]-3-[4-nitrophenyl]-5-phenyl tetrazolium chloride (INT) to form a red formazan dye. Concentrations of substrates were $0.05 \mathrm{mmol} / \mathrm{L}$ for xanthine and $0.025 \mathrm{mmol} / \mathrm{L}$ for INT. SOD activity was measured by the degree of inhibition of this reaction. After calculating the percent of inhibition using the related formula, SOD activity was calculated by comparing with the standard curve and was expressed as $\mathrm{U} / \mathrm{mg}$ protein. The inter-sample coefficient of variation and intra-assay variation were less than $8 \%$ (32).

\section{Glutathione peroxidase measurement}

GPx activity was determined using a RANSEL kit (Randox, Crumlin, UK). GPx catalyzes the oxidation of glutathione (at a concentration of $4 \mathrm{mmol} / \mathrm{L}$ ) by cumene hydroperoxide. In the presence of glutathione reductase (at a concentration of $\geq 0.5 \mathrm{mmol} / \mathrm{L}$ ) and $0.28 \mathrm{mmol} / \mathrm{L}$ of $\mathrm{NADPH}$, oxidized glutathione is immediately converted to the reduced form with concomitant oxidation of NADPH to $\mathrm{NAD}^{+}$. The decrease in absorbance at $340 \mathrm{~nm}\left(37^{\circ} \mathrm{C}\right)$ was measured using a spectrophotometer, and then GPx concentration was calculated and expressed as $\mathrm{U} / \mathrm{mg}$ protein. The intra- and inter-assay coefficient of variations were $7 \%$ and $8 \%$, respectively (7).

\section{Catalase measurement}

CAT activity was assayed by the method of Aebi (1). Briefly, to a quartz cuvette, $0.65 \mathrm{~mL}$ of the phosphate buffer $(50 \mathrm{mmol} / \mathrm{L} ; \mathrm{pH} 7.0)$ and $50 \mu \mathrm{L}$ sample were added, and the reaction was started by the addition of $0.3 \mathrm{~mL}$ of $30 \mathrm{mM}$ hydrogen peroxide $\left(\mathrm{H}_{2} \mathrm{O}_{2}\right)$. The decomposition of $\mathrm{H}_{2} \mathrm{O}_{2}$ was monitored at $240 \mathrm{~nm}$ at $25^{\circ} \mathrm{C}$. The CAT activity was calculated as $\mathrm{nM} \mathrm{H}_{2} \mathrm{O}_{2}$ consumed $/ \mathrm{min} / \mathrm{mg}$ of tissue protein.

\section{Statistical analysis}

Statistical analysis was performed by SPSS statistics v18 (IBM Corp., Armonk, NY, USA). All values were expressed as means \pm SEM. The between-group parameters were analyzed using two-way analysis of variance (ANOVA) followed by Tukey's post-hoc test. Differences were considered statistically significant when $p<0.05$.

\section{Results}

Effect of crocin and voluntary exercise on lipid peroxidation (malondialdehyde) levels As shown in Fig. 1 after 4 weeks of treatment of diabetic rats with crocin and voluntary exercise, the level of MDA decreased in treated diabetic rats as compared with the Dia group $(p<0.001)$. A comparison between the Dia-Cro-Exe group with Dia-Exe and Dia-Cro groups exhibited significant difference among these groups $(p<0.001$ and $p<0.01$, respectively).

\section{Effect of crocin and voluntary exercise on superoxide dismutase levels}

One-way ANOVA showed that the SOD levels were significantly higher in treated diabetic rats than in non-treated diabetic rats. Administration of crocin combined with exercise significantly increased SOD levels compared to Dia-Exe $(p<0.001)$ and Dia-Cro $(p<0.001)$ 


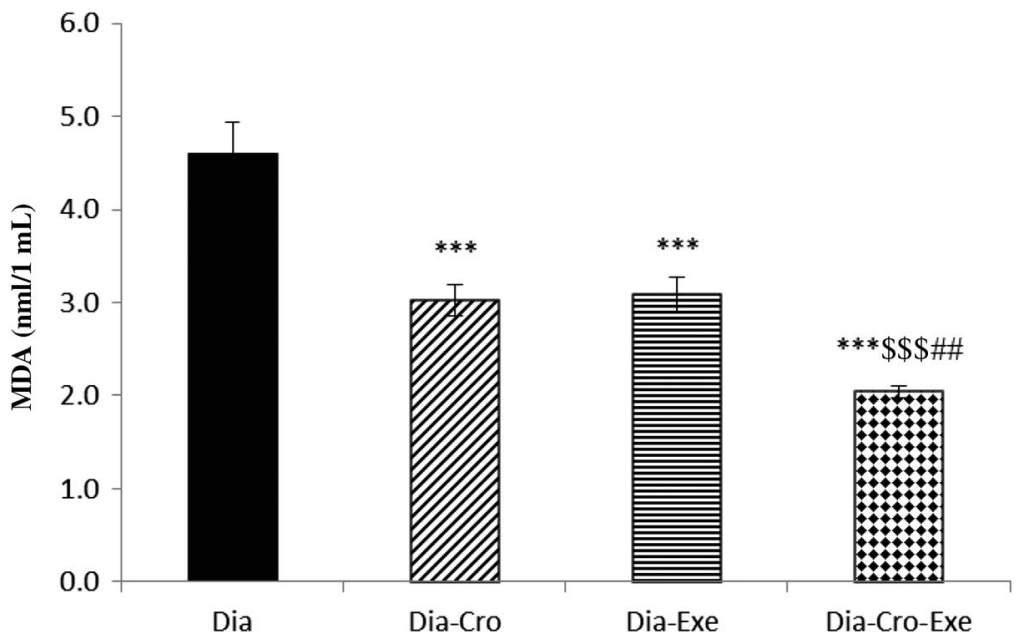

Fig. 1. Effect of crocin and voluntary exercise on malondialdehyde levels. Data are shown as mean \pm SEM for seven animals, $* * * p<0.001$ indicates a significant change compared with Dia group and ${ }^{\$ \$} p<0.001$ indicates a significant change compared with Dia-Exe group, and ${ }^{\# \#} p<0.01$ indicates a significant change compared with Dia-Cro group

groups (Fig. 2). Figure 2 also indicates that crocin combined with voluntary exercise had a synergistic effect on SOD levels in the heart tissue of diabetic rats.

Effect of crocin and voluntary exercise on glutathione peroxidase levels

After 8 weeks of administration of crocin or performing voluntary exercise, the level of GPx increased significantly in Dia-Exe, Dia-Cro, and Dia-Cro-Exe $(p<0.001)$ groups in

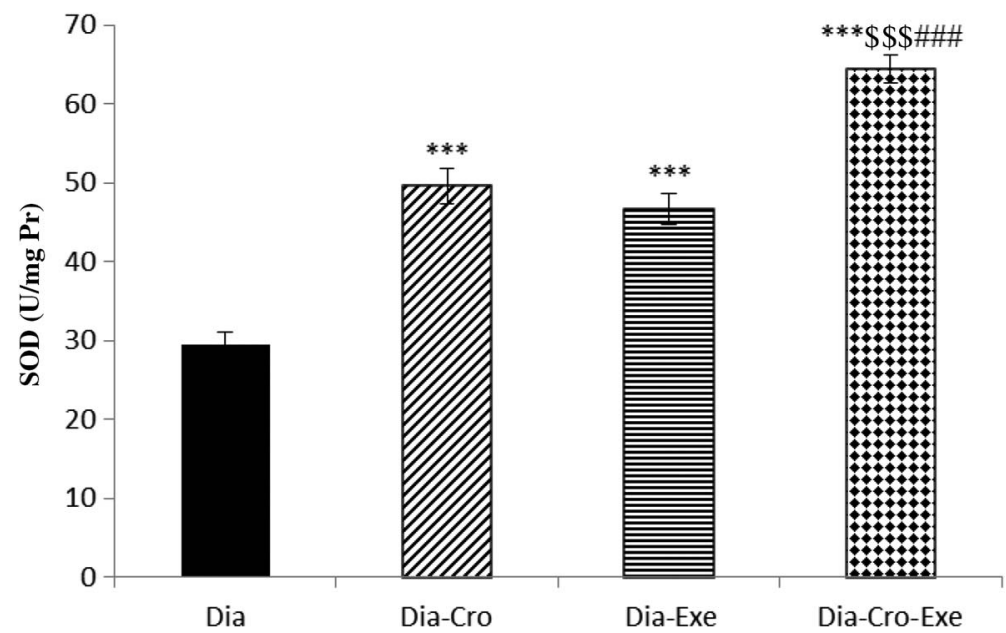

Fig. 2. Effect of crocin and voluntary exercise on superoxide dismutase levels. Data are shown as mean \pm S.E.M. for seven animals, $*^{* *} p<0.001$ indicates a significant change compared with Dia group, ${ }^{\$ \$} p<0.001$ indicates a significant change compared with Dia-Exe group, and ${ }^{\# \#} p<0.001$ indicates a significant change compared with Dia-Cro group 


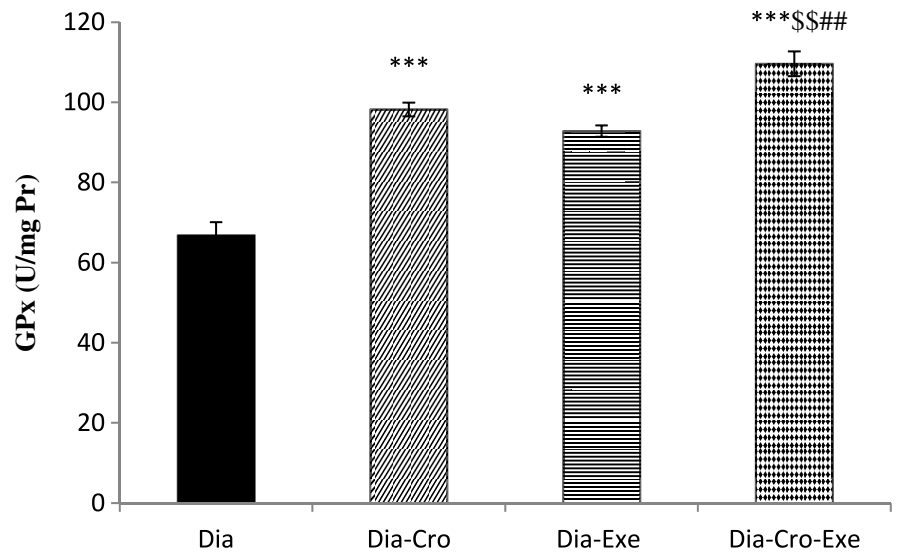

Fig. 3. Effect of crocin and voluntary exercise on glutathione peroxidase levels. Data are shown as mean \pm SEM for seven animals, *** $p<0.001$ indicates a significant change compared with Dia group, ${ }^{\$ \$} p<0.001$ indicates a significant change compared with Dia-Exe group, and ${ }^{\# \#} p<0.01$

indicates a significant change compared with Dia-Cro group

comparison with the Dia group (Fig. 3). A comparison between the Dia-Cro-Exe group with Dia-Exe and Dia-Cro groups exhibited significant difference among these groups $(p<0.01$ and $p<0.05$, respectively).

\section{Effect of crocin and voluntary exercise on catalase levels}

Results demonstrated that administration of crocin and performance of voluntary exercise enhanced significantly CAT activity in diabetic groups as compared with the non-treated diabetic rats (all $p<0.001$ ).

In the rats that underwent voluntary exercise and received simultaneously crocin for 8 weeks, the level of CAT activity significantly increased compared with Dia-Exe and Dia-Cro groups $(p<0.001)$ (Fig. 4).

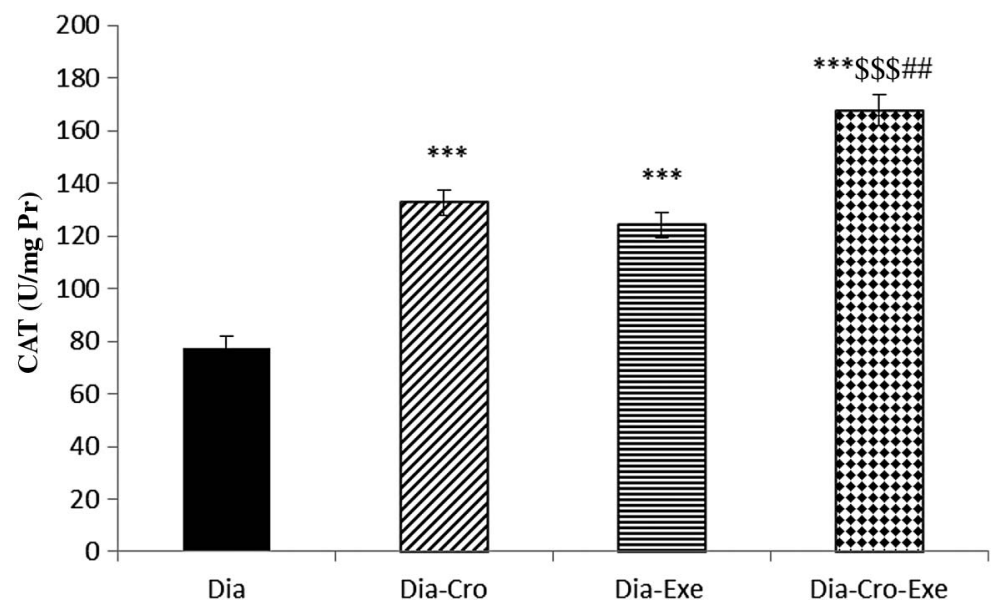

Fig. 4. Effect of crocin and voluntary exercise on catalase levels. Data are shown as mean \pm SEM for seven animals, $* * * p<0.001$ indicates a significant change compared with Dia group, ${ }^{\$ \$} p<0.001$ indicates a significant change compared with Dia-Exe group, and ${ }^{\# \#} p<0.01$ indicates a significant change compared with Dia-Cro group 


\section{Discussion}

The results of the present study indicate that oral administration of crocin in combination with voluntary exercise significantly decreased oxidative stress in the heart tissue of diabetic rats. We observed the significant elevation in GPx, CAT, and SOD with reduction in the MDA in both crocin- and voluntary exercise-treated diabetic rats compared with the non-treated diabetic group. Moreover, our data did demonstrate the favorable and synergistic effects of crocin in combination with voluntary exercise on reducing oxidative stress in the heart tissue of type 2 diabetic rats.

Type 2 diabetes is a worldwide health problem predisposing to markedly increased cardiovascular mortality and morbidity. Diabetes is diagnosed by the presence of hyperglycemia together with biochemical alterations such as increase in lipid peroxidation and oxidative stress (4). Hyperglycemia-induced oxidative stress is an important factor involved in diabetic-cardiac complications (34). Excessive levels of ROS or reduction of the antioxidant defenses, such as SODs, CAT, or GPx have been repeatedly described for type 2 DM (44).

In this study, we demonstrated that combination of crocin with voluntary exercise resulted in a higher increase of antioxidant levels and a more reduced lipid peroxidation rate (MDA content) than either of them alone in the heart of type 2 diabetic rats. It has been proven that exercise is a major therapeutic modality in the treatment of DM and it reduces cardiovascular complications (20). Clinical studies have shown that moderate intensity physical activity attenuates abnormal cardiac remodeling, improves functional capacity, and delay of onset of type 2 diabetes $(17,41)$. Roberts et al. (33) and Wycherley et al. (42) have reported that exercise alters the oxidative homeostasis of cells and tissues by decreasing the basal levels of oxidative damage and increasing resistance to oxidative stress in type 2 diabetes patients. Although moderate exercise increases the levels of antioxidant enzymes, it is considered that exhaustive physical activity causes inflammation and enhances oxidative stress associated with ROS (24). Therefore, in the present study, we prepared voluntary exercise facility for the animals, which is regarded as moderate intensity of physical activity. One important mechanism suggested for the beneficial effects of exercise training in type 2 diabetic patients is the upregulation of anti-inflammatory cytokine (38). Inflammation is a potent stimulator for the production of reactive species by macrophage and monocytes that inducing oxidative stress (23). Increase in oxidative stress-derived inflammation has been hypothesized to be a major mechanism in the pathogenesis and progression of type 2 diabetes (13). Studies have shown that an enhancement in oxidative stress jeopardizes function and structure of myocardium through mechanisms such as microvascular injury, abnormalities in calcium homeostasis, and endothelial dysfunction (40). In this study, we observed that voluntary exercise prevented an increase in myocardial lipid peroxidation and attenuated a decrease in antioxidant enzymes' activity in type 2 diabetic rats. This finding is in agreement with a previous study showing that non-exhaustive exercise such as voluntary exercise has beneficial effects on expression of certain antioxidant enzymes and substantially an increase in antioxidant enzymes' activity (30). Crocin was another intervention in this study that in combination with exercise increased antioxidant levels and reduced lipid peroxidation in the heart of type 2 diabetic rats. Crocin, one of the active components of saffron, has antioxidant and anti-inflammatory properties (22). In the present investigation, treatment with crocin inhibited the enhancement of lipid peroxidation in the heart tissue which was measured in terms of MDA, a stable metabolite of the free-radical-mediated lipid peroxidation cascade. 
This finding confirms its antioxidant role in the heart tissue of type 2 diabetic rats (21). Asri-Rezaei et al. (5) indicated that treatment with crocin reduced the content of MDA and total antioxidant capacity in STZ-induced diabetic rats. In addition, the protective effects of crocin on oxidative stress and hepatic injury in STZ-induced diabetic rats have been reported (3). The data of our study revealed that daily treatment of crocin could enhance antioxidant status of the heart tissue of rats with high-fat diet-induced type 2 diabetes, which may be used as a therapeutic method in the diabetic patients. It can be suggested that regular administration of crocin combined with voluntary exercise may induce beneficial effects in type 2 diabetic patients.

\section{Conclusion}

The present study results confirmed that crocin combined with voluntary exercise had protective influence in the heart tissue of type $2 \mathrm{DM}$ in rats. Marked reduction in lipid peroxidation (indicated by MDA) and an enhancement in levels of antioxidant enzymes following the combination of crocin with voluntary exercise indicate their powerful antioxidant activities.

\section{Acknowledgement}

This work was supported by a grant from the Student Research Committee, Tabriz University of Medical Sciences, Tabriz, Iran.

\section{REFERENCES}

1. Aebi H: Catalase in vitro. Methods Enzymol. 105, 121-126 (1984)

2. Al-awar A, Kupai K, Veszelka M, Szücs G, Attieh Z, Murlasits Z, Török S, Pósa A, Varga C: Experimental diabetes mellitus in different animal models. J. Diabetes Res. 2016, 9051426 (2016)

3. Altinoz E, Oner Z, Elbe H, Turkoz Y, Cigremis Y: Protective effect of saffron (its active constituent, crocin) on oxidative stress and hepatic injury in streptozotocin induced diabetic rats. Gene Ther. Mol. Biol. 16, 160-171 (2014)

4. Ashour M, Salem S, Hassaneen H, El-Gadban H, Elwan N, Awad A, Basu TK: Antioxidant status and insulindependent diabetes mellitus (IDDM). J. Clin. Biochem. Nutr. 26, 99-107 (1999)

5. Asri-Rezaei S, Tamaddonfard E, Ghasemsoltani-Momtaz B, Erfanparast A, Gholamalipour S: Effects of crocin and zinc chloride on blood levels of zinc and metabolic and oxidative parameters in streptozotocin-induced diabetic rats. Avicenna J. Phytomed. 5, 403 (2015)

6. Assimopoulou A, Sinakos Z, Papageorgiou V: Radical scavenging activity of Crocus sativus L. Extract and its bioactive constituents. Phytother. Res. 19, 997-1000 (2005)

7. Badalzadeh R, Yavari R, Chalabiani D: Mitochondrial ATP-sensitive $\mathrm{K}^{+}$channels mediate the antioxidative influence of diosgenin on myocardial reperfusion injury in rat hearts. Gen. Physiol. Biophys. 34, 323-329 (2015)

8. Brocardo PS, Boehme F, Patten A, Cox A, Gil-Mohapel J, Christie BR: Anxiety- and depression-like behaviors are accompanied by an increase in oxidative stress in a rat model of fetal alcohol spectrum disorders: protective effects of voluntary physical exercise. Neuropharmacology 62, 1607-1618 (2012)

9. Brownlee M: Biochemistry and molecular cell biology of diabetic complications. Nature 414, 813-820 (2001)

10. Busik JV, Mohr S, Grant MB: Hyperglycemia-induced reactive oxygen species toxicity to endothelial cells is dependent on paracrine mediators. Diabetes 57, 1952-1965 (2008)

11. Eddouks M, Maghrani M, Lemhadri A, Ouahidi M-L, Jouad H: Ethnopharmacological survey of medicinal plants used for the treatment of diabetes mellitus, hypertension and cardiac diseases in the south-east region of morocco (tafilalet). J. Ethnopharmacol. 82, 97-103 (2002)

12. Ellison GM, Waring CD, Vicinanza C, Torella D: Physiological cardiac remodelling in response to endurance exercise training: cellular and molecular mechanisms. Heart 98, 5-10 (2011) 
13. Evans JL, Goldfine ID, Maddux BA, Grodsky GM: Oxidative stress and stress-activated signaling pathways: a unifying hypothesis of type 2 diabetes. Endocr. Rev. 23, 599-622 (2002)

14. Fraga CG, Leibovitz BE, Tappel AL: Lipid peroxidation measured as thiobarbituric acid-reactive substances in tissue slices: characterization and comparison with homogenates and microsomes. Free Radic. Biol. Med. 4, 155-161 (1988)

15. Fubini B, Hubbard A: Reactive oxygen species (ROS) and reactive nitrogen species (RNS) generation by silica in inflammation and fibrosis. Free Radic. Biol. Med. 34, 1507-1516 (2003)

16. Ghorbanzadeh V, Mohammadi M, Dariushnejad H, Chodari L, Mohaddes G: Effects of crocin and voluntary exercise, alone or combined, on heart VEGF-A and HOMA-IR of HFD/STZ induced type 2 diabetic rats. J. Endocrinol. Invest. 39, 1179-1186 (2016)

17. Giannuzzi P, Temporelli PL, Corrà U, Tavazzi L, Group E-CS: Antiremodeling effect of long-term exercise training in patients with stable chronic heart failure results of the exercise in left ventricular dysfunction and chronic heart failure (ELVD-CHF) trial. Circulation 108, 554-559 (2003)

18. Goyal S, Arora S, Sharma A, Joshi S, Ray R, Bhatia J, Kumari S, Arya D: Preventive effect of crocin of Crocus sativus on hemodynamic, biochemical, histopathological and ultrastuctural alterations in isoproterenol-induced cardiotoxicity in rats. Phytomedicine 17, 227-232 (2010)

19. He S-Y, Qian Z-Y, Tang F-T, Wen N, Xu G-L, Sheng L: Effect of crocin on experimental atherosclerosis in quails and its mechanisms. Life Sci. 77, 907-921 (2005)

20. Hilberg T: Physical activity in the prevention of cardiovascular diseases-epidemiology and mechanisms. Hämostaseologie 28, 9-15 (2008)

21. Hosseinzadeh H, Sadeghnia HR, Ziaee T, Danaee A: Protective effect of aqueous saffron extract (Crocus sativus L.) and crocin, its active constituent, on renal ischemia-reperfusion-induced oxidative damage in rats. J. Pharm. Pharm. Sci. 8, 387-393 (2005)

22. Hosseinzadeh H, Younesi HM: Antinociceptive and anti-inflammatory effects of Crocus sativus L. stigma and petal extracts in mice. BMC Pharmacol. 2, 7 (2002)

23. Huang W, Glass CK: Nuclear receptors and inflammation control: molecular mechanisms and pathophysiological relevance. Arterioscler. Thromb. Vasc. Biol. 30, 1542-1549 (2010)

24. Ishikawa Y, Gohda T, Tanimoto M, Omote K, Furukawa M, Yamaguchi S, Murakoshi M, Hagiwara S, Horikoshi S, Funabiki K, Tomino Y: Effect of exercise on kidney function, oxidative stress, and inflammation in type 2 diabetic Kk-A(y) mice. Exp. Diabetes Res. 2012, 702948 (2012)

25. Ke Z, Yip SP, Li L, Zheng X-X, Tong K-Y: The effects of voluntary, involuntary, and forced exercises on brain-derived neurotrophic factor and motor function recovery: a rat brain ischemia model. PLoS One 6, e16643 (2011)

26. Kupai K, Szabó R, Veszelka M, Al Awar A, Török S, Csonka A, Baráth Z, Pósa A, Varga C: Consequences of exercising on ischemia-reperfusion injury in type 2 diabetic Goto-Kakizaki rat hearts: role of the HO/NOS system. Diabetol. Metab. Syndr. 7, 85 (2015)

27. Laakso M: Cardiovascular disease in type 2 diabetes: challenge for treatment and prevention. J. Intern. Med. 249 , 225-235 (2001)

28. Lakka TA, Venalainen JM, Rauramaa R, Salonen R, Tuomilehto J, Salonen JT: Relation of leisure-time physical activity and cardiorespiratory fitness to the risk of acute myocardial infarction in men. N. Engl. J. Med. 330, 1549-1554 (1994)

29. Lee S, Park Y, Zhang C: Exercise training prevents coronary endothelial dysfunction in type 2 diabetic mice. Am. J. Biomed. Sci. 3, 241-252 (2011)

30. Leonardo-Mendonça RC, Concepción-Huertas M, Guerra-Hernández E, Zabala M, Escames G, AcuñaCastroviejo D: Redox status and antioxidant response in professional cyclists during training. Eur. J. Sport Sci. 14, 830-838 (2014)

31. Mashmoul M, Azlan A, Yusof BNM, Khaza'ai H, Mohtarrudin N, Boroushaki MT: Effects of saffron extract and crocin on anthropometrical, nutritional and lipid profile parameters of rats fed a high fat diet. J. Funct. Foods 8 , 180-187 (2014)

32. Pari L, Monisha P, Jalaludeen AM: Beneficial role of diosgenin on oxidative stress in aorta of streptozotocin induced diabetic rats. Eur. J. Pharmacol. 691, 143-150 (2012)

33. Roberts CK, Won D, Pruthi S, Barnard RJ: Effect of a diet and exercise intervention on oxidative stress, inflammation and monocyte adhesion in diabetic men. Diabetes Res. Clin. Pract. 73, 249-259 (2006)

34. Rosa CM, Xavier NP, Henrique Campos D, Fernandes A, Cezar M, Martinez PF, Cicogna AC, Gimenes C, Gimenes R, Okoshi MP: Diabetes mellitus activates fetal gene program and intensifies cardiac remodeling and oxidative stress in aged spontaneously hypertensive rats. Cardiovasc. Diabetol. 12, 152 (2013) 
35. Samarghandian S, Borji A, Delkhosh MB, Samini F: Safranal treatment improves hyperglycemia, hyperlipidemia and oxidative stress in streptozotocin-induced diabetic rats. J. Pharm. Pharm. Sci. 16, 352-362 (2013)

36. Santini SA, Marra G, Giardina B, Cotroneo P, Mordente A, Martorana GE, Manto A, Ghirlanda G: Defective plasma antioxidant defenses and enhanced susceptibility to lipid peroxidation in uncomplicated IDDM. Diabetes 46, 1853-1858 (1997)

37. Srinivasan K, Viswanad B, Asrat L, Kaul C, Ramarao P: Combination of high-fat diet-fed and low-dose streptozotocin-treated rat: a model for type 2 diabetes and pharmacological screening. Pharmacol. Res. 52, 313-320 (2005)

38. Timmerman KL, Flynn MG, Coen PM, Markofski MM, Pence BD: Exercise training-induced lowering of inflammatory $(\mathrm{CD} 14+\mathrm{CD} 16+)$ monocytes: a role in the anti-inflammatory influence of exercise? J. Leukoc. Biol. 84, 1271-1278 (2008)

39. Tsalouhidou S, Petridou A, Mougios V: Effect of chronic exercise on DNA fragmentation and on lipid profiles in rat skeletal muscle. Exp. Physiol. 94, 362-370 (2009)

40. Watanabe K, Thandavarayan RA, Harima M, Sari FR, Gurusamy N, Veeraveedu PT, Mito S, Arozal W, Sukumaran V, Prasath Laksmanan A: Role of differential signaling pathways and oxidative stress in diabetic cardiomyopathy. Curr Cardiol. Rev. 6, 280-290 (2010)

41. Wisløff U, Støylen A, Loennechen JP, Bruvold M, Rognmo Ø, Haram PM, Tjønna AE, Helgerud J, Slørdahl SA, Lee SJ: Superior cardiovascular effect of aerobic interval training versus moderate continuous training in heart failure patients a randomized study. Circulation 115, 3086-3094 (2007)

42. Wycherley T, Brinkworth G, Noakes M, Buckley J, Clifton P: Effect of caloric restriction with and without exercise training on oxidative stress and endothelial function in obese subjects with type 2 diabetes. Diabetes Obes. Metab. 10, 1062-1073 (2008)

43. Xi L, Qian Z, Xu G, Zheng S, Sun S, Wen N, Sheng L, Shi Y, Zhang Y: Beneficial impact of crocetin, a carotenoid from saffron, on insulin sensitivity in fructose-fed rats. J. Nutr. Biochem. 18, 64-72 (2007)

44. Yang H, Jin X, Lam K, Wai C, Yan S-K: Oxidative stress and diabetes mellitus. Clin. Chem. Lab. Med. 49, 1773-1782 (2011)

45. Yang Y-C, Hwang J-H, Hong S-J, Hsu H-K: Enhancement of glucose uptake in 3T3-L1 adipocytes by Toona sinensis leaf extract. Kaohsiung J. Med. Sci. 19, 327-332 (2003)

46. Youn J-Y, Park H-Y, Cho K-H: Anti-hyperglycemic activity of Commelina communis L.: inhibition of $\alpha$-glucosidase. Diabetes Res. Clin. Pract. 66, S149-S155 (2004)

47. Zhang M, Lv X-Y, Li J, Xu Z-G, Chen L: The characterization of high-fat diet and multiple low-dose streptozotocin induced type 2 diabetes rat model. Exp. Diabetes Res. 2008, 704045 (2009)

48. Zheng Y-Q, Liu J-X, Wang J-N, Xu L: Effects of crocin on reperfusion-induced oxidative/nitrative injury to cerebral microvessels after global cerebral ischemia. Brain Res. 1138, 86-94 (2007)

49. Zimmet PZ, McCarty DJ, de Courten MP: The global epidemiology of non-insulin-dependent diabetes mellitus and the metabolic syndrome. J. Diabetes Complications 11, 60-68 (1997) 